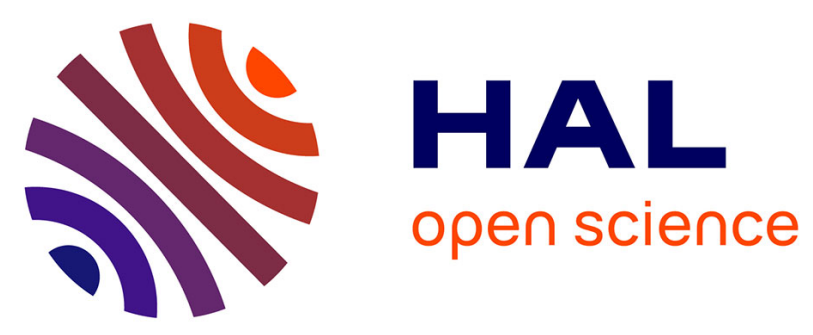

\title{
Deterministic model of PWR fast fluence for uncertainity propagations with the code APOLLO3
}

P. Mosca, L. Clouvel, T. Lacaze, S. Lahaye, J.-J. Lautard, A.-M. Baudron

\section{To cite this version:}

P. Mosca, L. Clouvel, T. Lacaze, S. Lahaye, J.-J. Lautard, et al.. Deterministic model of PWR fast fluence for uncertainity propagations with the code APOLLO3. Mary Helen Sparks; K. Russell DePriest; David W. Vehar. Reactor Dosimetry - 16th International Symposium (STP 1608), 1608, ASTM International, 100 Barr Harbor Drive, PO Box C700, West Conshohocken, PA 19428-295, pp.446-457, 2017, 978-0-8031-7661-4. 10.1520/STP160820170048 . cea-02421728

\section{HAL Id: cea-02421728 \\ https://hal-cea.archives-ouvertes.fr/cea-02421728}

Submitted on 20 Dec 2019

HAL is a multi-disciplinary open access archive for the deposit and dissemination of scientific research documents, whether they are published or not. The documents may come from teaching and research institutions in France or abroad, or from public or private research centers.
L'archive ouverte pluridisciplinaire HAL, est destinée au dépôt et à la diffusion de documents scientifiques de niveau recherche, publiés ou non, émanant des établissements d'enseignement et de recherche français ou étrangers, des laboratoires publics ou privés. 


\title{
Deterministic model of PWR fast fluence for uncertainity propagations with the code $A P O L L O 3^{\circledR}$
}

\author{
Pietro Mosca ${ }^{1}$, Laura Clouvel$^{2}$, Théophile Lacaze ${ }^{2}$, Sébastien Lahaye ${ }^{2}$, Jean Jacques \\ Lautard $^{2}$ and Anne Marie Baudron ${ }^{2}$
}

\begin{abstract}
The fast neutron fluence and the corresponding uncertainty are important parameters for reactor pressure vessel life time. This article presents one model, under development at CEA (Commissariat à l'Energie Atomique et aux Energies Alternatives), to carry out with the deterministic code APOLLO ${ }^{\circledR}$ uncertainty calculations of the fast fluence for PWR irradiation surveillance. All calculations are made by MINARET, a 3D-SN solver of the APOLLO ${ }^{\circledR}$ code which uses the discontinuous Galerkin finite elements approximation. The spatial mesh is unstructured and the transport calculations are parallelized with respect to the angular directions. In this numerical scheme, the multigroup cross-sections are sub-group self-shielded and collapsed over a dedicated energy mesh optimized by the Adaptive Energy Mesh Constructor (AEMC). Results from this model are encouraging with respect to the Monte Carlo reference TRIPOLI- $4^{\circledR}$. The integral of the flux over $1 \mathrm{MeV}$ in the locations of interest (surveillance capsule and vessel) is calculated in less than 20 minutes with an error lower than $1 \%$. Some examples of uncertainty calculations associated to design parameters in which the MINARET solver is coupled to the CEA uncertainty and sensitivity platform URANIE are also provided.
\end{abstract}

\section{Keywords}

RPV, NEUTRON FLUENCE, UNCERTAINTY, APOLLO ${ }^{\circledR}{ }^{\circledR}$, URANIE, AEMC.

\section{INTRODUCTION}

The fast neutron fluence and the corresponding uncertainties are important parameters for the reactor pressure vessel life time. Usually for this kind of studies, reference tools are based on Monte Carlo codes. However, the CPU time required is still not reasonable for uncertainty and sensitivity analyses. In this perspective, this article presents the model, under development at CEA (Commissariat à l'Energie Atomique et aux Energies Alternatives), to carry out with the deterministic code APOLLO3 ${ }^{\circledR}$ [1] uncertainty calculations of the fast fluence for PWR irradiation surveillance.

The new numerical scheme is based on the 3D-SN solver MINARET [2] of the APOLLO3 ${ }^{\circledR}$ code which uses the discontinuous Galerkin finite elements approximation. The spatial mesh is unstructured and the transport calculations are parallelized with respect to the angular directions. In this scheme, the multigroup cross-sections are sub-group self-shielded and collapsed over a dedicated energy mesh optimized by the Adaptive Energy Mesh Constructor (AEMC) [3].

The structure of the paper is as follow. First the choice of the multigroup library and the

\footnotetext{
${ }^{1}$ DEN/DANS/DM2S/SERMA/LLPR, Bâtiment 470, 91191 Gif sur Yvette Cedex, France, pietro.mosca@ cea.fr

${ }^{2}$ DEN/DANS/DM2S/SERMA/LLPR, Bâtiment 470, 91191 Gif sur Yvette Cedex, France
} 
optimization of the energy mesh to collapse cross-sections are described. Second the validation of the deterministic fast fluence scheme respecting the Monte Carlo reference TRIPOLI- $4^{\circledR}$ [4] is shown on a three-dimensional PWR geometry. Then an example of uncertainty propagation coupling MINARET to the uncertainty and sensitivity platform URANIE [5] is presented and results are discussed.

\section{VALIDATION OF THE MULTIGROUP LIBRARY}

As a first step for the development of the deterministic fast fluence scheme, the choice of the multigroup library for the production of the core collapsed cross-section library is done. The considered libraries are mainly based on the JEFF3.1.1 evaluation and are declined over optimized 300, 600, 1200 group energy meshes by AEMC for fast reactor systems [3], [6]. A simplified slab model, which corresponds to a section cut of the reactor going from the core peripheral to the inner part of the vessel, is used to evaluate the accuracy of these different multigroup libraries. Vacuum boundary conditions are applied on the right end side and an external source distributed in energy according to the fissile spectra of the core is set on the left end side. The transport calculations are carried out with the APOLLO2 [7] discrete ordinates solver with a $S 32$ angular discretization and a $P 5$ approximation for the scattering cross sections. Cross-sections of all the light nuclides of the steel are subgroup self-shielded and differentiated per media of the slab. Table 1 shows the accuracy of the different deterministic solutions with respect to the reference TRIPOLI- ${ }^{\circledR}$ using as discriminant parameter the total flux over $1 \mathrm{MeV}$, noted $\Phi_{1 \mathrm{MeV}}$ in this work. One can notice that passing from 300 to 600 group library the accuracy is almost increased of a factor two while a further energy mesh refining does not much more improve the accuracy of the solution. Fig. 1 shows that the corresponding multigroup fluxes in the vessel are within TRIPOLI- $4^{\circledR}$ error bars in the energy range between 1 and $20 \mathrm{MeV}$.

These results validate the use of the 600-group library for the production of the core collapsed cross-section library.

Table 1 : Total flux over $1 \mathrm{MeV}$ in a slab obtained running APOLLO2 with different multigroup libraries and compared to TRIPOLI-4 ${ }^{\circledR}$ reference. A2 and T4 stand for APOLLO2 and TRIPOLI-4 ${ }^{\circledR}$ respectively.

\begin{tabular}{|c|c|c|c|c|}
\hline $\mathbf{1}-\boldsymbol{\Phi}_{\mathbf{1 M e V}}{ }^{\mathbf{A 2}} / \boldsymbol{\Phi}_{\mathbf{1 M e V}}$ & $\mathbf{3 0 0}$ groups & $\mathbf{6 0 0}$ groups & $\mathbf{1 2 0 0}$ groups & $\mathbf{3 \sigma}$ (T4) \\
\hline Capsule & $-1.48 \%$ & $-0.81 \%$ & $-0.69 \%$ & $0.38 \%$ \\
\hline Vessel & $-1.25 \%$ & $-0.69 \%$ & $-0.44 \%$ & $1.20 \%$ \\
\hline
\end{tabular}




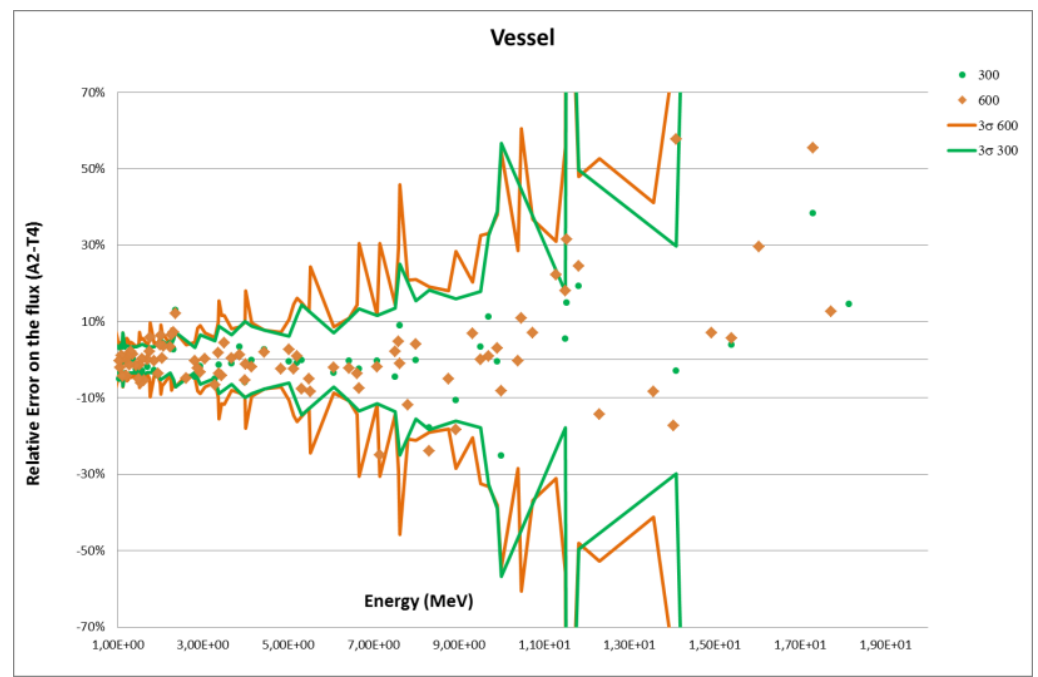

Figure 1 Multigroup flux over $1 \mathrm{MeV}$ in the vessel medium of the slab obtained running APOLLO2 with 300 and 600-group libraries and compared to TRIPOLI-4 ${ }^{\circledR}$ reference. A2 and T4 stand for APOLLO2 and TRIPOLI-4 ${ }^{\circledR}$ respectively.

\section{OPTIMIZATION OF THE ENERGY MESH FOR CROSS-SECTION COLLAPSING}

Since the memory required by the 600 group library is too huge to be used in a three-dimensional fluence core calculation, a cross-section collapsing is mandatory. To address such a problem, the approach described in [8] has been adapted to the fluence context. The optimization is accomplished on the slab geometry of the previous section, considering a pure uranium and plutonium fission source. The energy mesh bounds are adapted by AEMC [3] in order to minimize the errors between two successive SN transports. The reference SN calculation is carried out over the fine 600-group energy mesh and the approximate one is obtained from collapsed cross-sections by flux homogenization over a coarser energy mesh.

To accomplish the optimization, it is defined the following functional that depends on the coarse mesh $M_{C}$ of $N G$ groups:

$$
F\left(M_{c}\right)=\sum_{n=1}^{N} \alpha_{n}\left[F_{n}\left(M_{c}\right)\right]^{2}+\sum_{k=1}^{N G}\left[G_{k}\left(M_{c}\right)\right]^{2},
$$

where $N=N I \times N M \times N R \times N G \times N C$ is the total number of components, $N I$ is the total number of isotopes, $N M$ is the total number of media, $N R$ represents the total number of reactions ( $N R=2$ corresponding to absorption and scattering) and $N C$ is the total number of problems to be considered in the optimization ( $N C=2$ for the two types of sources). The $F_{n}\left(M_{c}\right)$ components represent the discrepancy between the reference isotopic reaction rate and its approximate value $T_{\rho, x, i}^{r, G}, T_{\rho, x, i}^{a, G}$ renormalized to the corresponding total isotopic reaction rates $T_{\rho, x, i}^{r}\left(M_{c}\right), T_{\rho, x, i}^{a}\left(M_{c}\right)$ :

$$
\begin{gathered}
F_{n}(M c)=\left[\frac{T_{\rho, i}^{r, G}\left(M_{c}\right)}{T_{\rho, x, i}^{r}\left(M_{c}\right)}-\frac{T_{\rho, x, i}^{a, G}\left(M_{c}\right)}{T_{\rho, x, i}^{a}\left(M_{c}\right)}\right], \quad \alpha_{n}=\frac{T_{\rho, x, i}^{r}\left(M_{c}\right)}{T_{\rho, i}\left(M_{c}\right)}, \quad T_{\rho, i}^{r, a}\left(M_{c}\right)=\sum_{x} T_{\rho, x, i}^{r, a}\left(M_{c}\right), \\
1 \leq \rho \leq N R, 1 \leq \mathrm{G} \leq N G, 1 \leq i \leq N I, 1 \leq x \leq N M \times N C .
\end{gathered}
$$

The use of both the weights $\alpha_{n}$ and the renormalization is justified in [8]. The $G_{k}\left(M_{c}\right)$ components measure the discrepancy between the reference and the approximate leakage terms: 


$$
G_{n}(M c)=\left[\frac{J^{r, G}\left(M_{c}\right)}{J^{r}\left(M_{c}\right)}-\frac{J^{a, G}\left(M_{c}\right)}{J^{a}\left(M_{c}\right)}\right]
$$

The 600-group library has 96 groups above $1 \mathrm{MeV}$, the remaining groups beneath, which are useless with regard to the problem being treated, are collapsed in a unique group. Indeed, the flux responsible for damaging the vessel is currently defined as the total neutron flux greater than $1 \mathrm{MeV}$. AEMC has therefore determined a coarse mesh consisting of a single group between $10^{-11} \mathrm{MeV}$ and $1 \mathrm{MeV}$ and $(\mathrm{NG}-1)$ energy groups greater than $1 \mathrm{MeV}$ (with $\mathrm{NG}<96$ the available number of groups).

Fig. 2 shows the dependency of the functional $F_{n}(M c)$ with respect to the number of groups. One can notice that the accuracy does not improve itself over 19 groups. The same tendency has been verified comparing $\Phi_{1 \mathrm{MeV}}$, which are obtained with different optimized energy meshes, and the Monte Carlo reference.

These results lead to the use of the 19-group optimized energy mesh in the core fluence calculations. This energy mesh contains 1 group between $10^{-11}$ and $1 \mathrm{MeV}$ and 18 groups between 1 and $20 \mathrm{MeV}$.

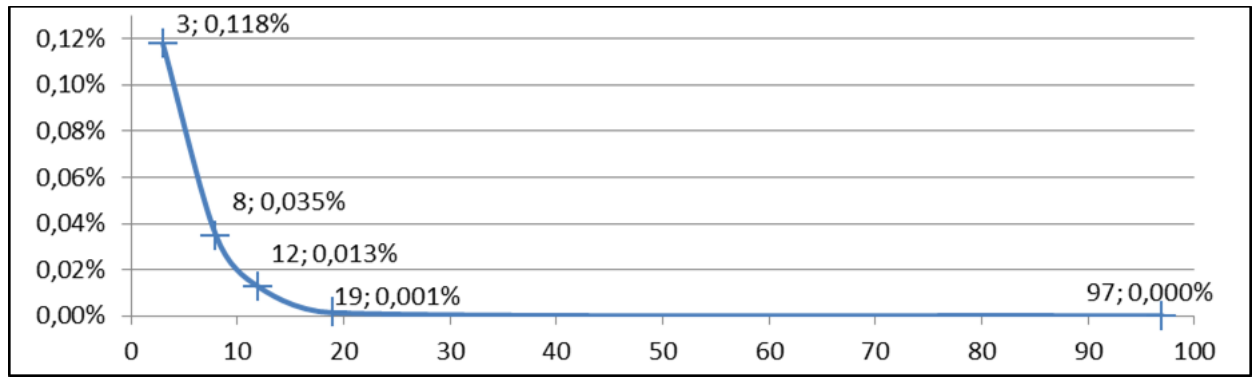

Figure 2 Funtional value of the energy mesh optimization versus the number of groups

\section{VALIDATION OF THE DETERMINISTIC FLUENCE MODEL}

The validation of the deterministic fluence model is carried out modeling one eights of a 900 MWe PWR core. The reflector geometry is obtained by axial extrusion of five radial basic geometries that model the baffles, the surveillance capsules, the stiffeners, the cold and the hot water part at the bottom and the top of the core (Fig. 3). The core is composed of 26 assemblies and each assembly is a standard 17x17 UO2 homogeneous pin cells. The homogenization is justified by the fact that neutron mean free path in UO2 fuel and in borated hot water is higher than the size of the cells at energies beyond $1 \mathrm{MeV}$. Only the four last peripheral assemblies of the core are taken into account in the transport calculation (Fig. 3). This simplification reduces of one third the CPU time preserving the accuracy of the solution because $99 \%$ of the fluence in the vessel and in the surveillance capsules is due to neutrons from the peripheral assemblies.

The power distribution in the core is an input datum which is directly converted into a neutron source radially homogenized on the fuel cells and discretized into 56 axial planes.

The axial temperature profiles of the water in the core and in the reflector correspond to standard operating conditions, elsewhere only average operating temperature values are considered. Since Doppler effect is negligible on light nuclei and also on heavy nuclei above the resonance energy range (energy higher than $300 \mathrm{keV}$ ), the water density is the only considered physical parameter to be modified by the temperature. All the cross-sections are calculated at the average operating 
temperatures.

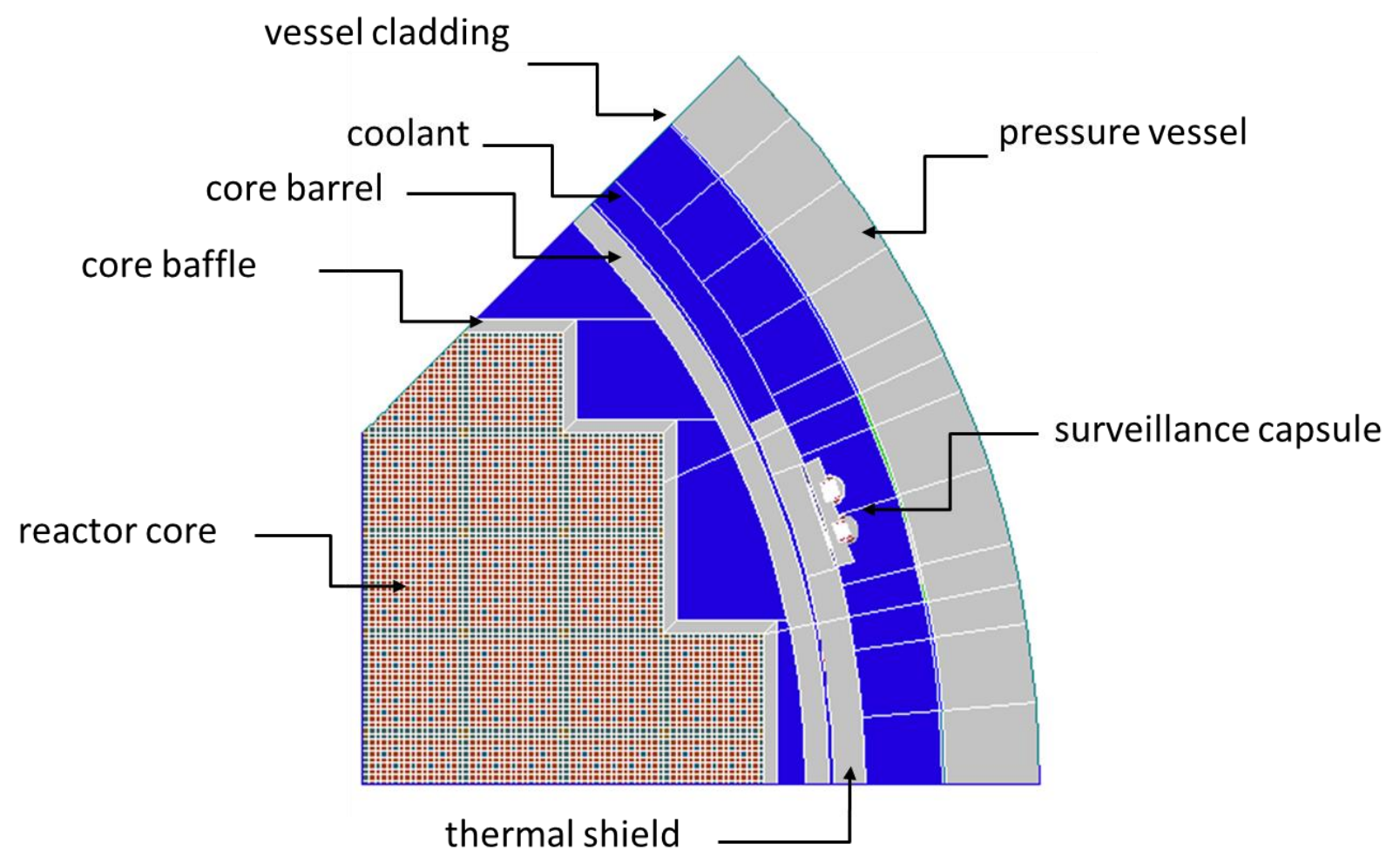

Figure 3: Two-dimensional geometry of the PWR core

All the transport calculations are carried out by the MINARET [2] 3D SN-solver of the APOLLO ${ }^{\circledR}$ code. This solver uses the discontinuous Galerkin finite elements approximation, the spatial mesh is unstructured and the transport calculations are parallelized with respect to the angular directions. The solution in each cell can be radially and axially expanded up to a polynomial of order 1. The solution method is iterative and accelerated by DSA (Diffusion Synthetic Acceleration). The total FME (Finite Element Matrix) is solved by transport sweeps without spatial decomposition keeping only in memory the matrices of the DSA.

The multigroup cross-sections are obtained collapsing the sub-group self-shielded cross-sections of the 600-group library with the flux of the slab model over the optimized 19 group-energy mesh.

The MINARET calculations are carried out using a S32 angular discretization, a P3 approximation for the scattering cross sections, a radial mesh size of $2 \mathrm{~cm}$, an axial mesh size 10 $\mathrm{cm}$. The radial and the axial polynomial order are set equal to 1 and 0 respectively and the relative error per group on the flux is imposed lower than $10^{-4}$. These parameters are issued of a preliminary convergence analysis of the solution.

The reference calculation is carried out with the TRIPOLI- ${ }^{\circledR}$ Monte Carlo code using a geometrical description without homogenization of the core. Multigroup and pointwise crosssections are issued from the processing of the JEFF3.1.1 evaluation.

From Table 2 one can observe that relative error on the total flux over $1 \mathrm{MeV}$ is lower than $1 \%$. Fig. 4 shows that the multigroup flux discrepancy in the vessel is lower than 5\% between 1 and 
$20 \mathrm{MeV}$. These results prove that the higher complexity of the 3D core test does not impact the accuracy of the solution because it is comparable to the slab test (cf. Fig. 1).

The APOLLO ${ }^{\circledR}{ }^{\circledR}$ transport calculation took 20 minutes and required a total memory of $113 \mathrm{~Gb}$ with a MPI (Message Passing Interface) parallel computing on a LINUX CenOS6.4 cluster of 4 processors with 20 cores each. The corresponding TRIPOLI- $4^{\circledR}$ reference calculations required 6 hours with the same demand of processor resources.

These results support the use of MINARET to perform uncertainty studies of neutron fluence using a Monte Carlo approach.

Table 2 : Total flux over $1 \mathrm{MeV}$ for the 900 MWe PWR obtained with APOLLO3 ${ }^{\circledR}$ and compared to the reference TRIPOLI-4 ${ }^{\circledR}$. A3 and T4 stand for APOLLO3 ${ }^{\circledR}$ and TRIPOLI-4 ${ }^{\circledR}$ respectively.

\begin{tabular}{|c|c|c|}
\hline Medium & $\mathbf{1}-\boldsymbol{\Phi}_{1 \mathrm{MeV}}{ }^{\mathrm{A} 3} / \mathbf{\Phi}_{1 \mathrm{MeV}}{ }^{\mathrm{T4}}$ & $3 \sigma(\mathrm{T} 4)$ \\
\hline Vessel & $0.61 \%$ & $0.24 \%$ \\
\hline Capsule $20^{\circ}$ & $0.86 \%$ & $0.09 \%$ \\
\hline Capsule $17^{\circ}$ & $0.30 \%$ & $0.09 \%$ \\
\hline
\end{tabular}

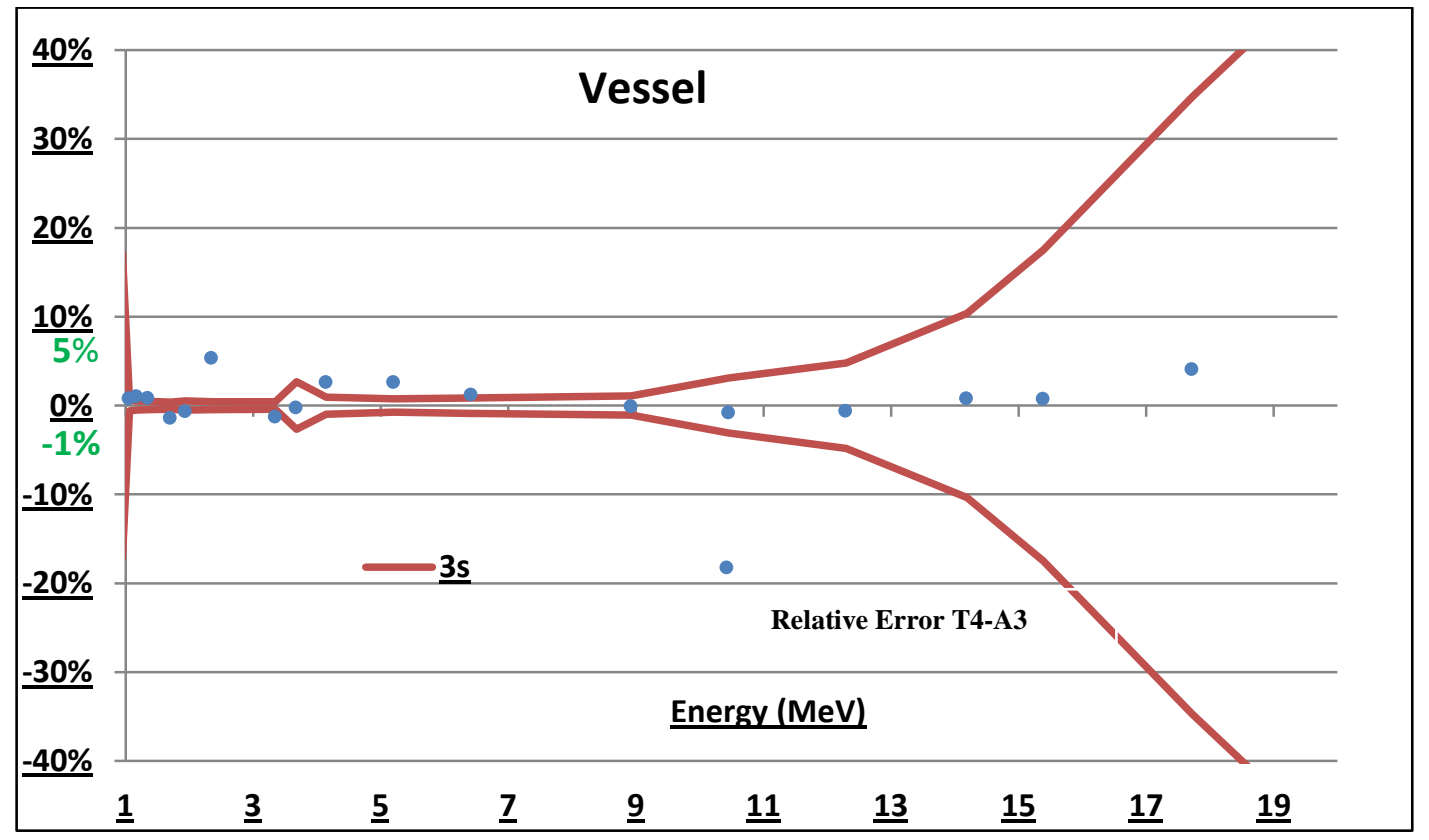

Figure 4 : Multigroup flux over $1 \mathrm{MeV}$ in the vessel of 900 MWe PWR obtained with APOLLO3 ${ }^{\circledR}$ and compared to the reference TRIPOLI-4 ${ }^{\circledR}$. A3 and T4 stand for APOLLO3 ${ }^{\circledR}$ and TRIPOLI-4 ${ }^{\circledR}$ respectively. 


\section{UNCERTAINTY PROPAGATION}

The deterministic fluence scheme is used in order to lead a simplified uncertainty propagation to evaluate the impact of technological parameters (manufacturing tolerance of in-vessel components and water temperature). This study is carried out coupling the MINARET solver to the CEA uncertainty and sensitivity platform URANIE [5] which pilots the design of experiment (DOE).

Table 3 shows the perturbed parameters and the corresponding variations in the study. In our case, we consider that the variation of the uncertain variables follows a uniform law centered on the nominal value; that is, the realization of the geometric values in the finite set, defined by the uncertainties, is equally probable. For temperature sampling, the perturbation is the same at each axial step of the core, since total power of the reactor is not an uncertain variable of the study. The Latin hypercube sampling method is used by URANIE for the sampling. The DOE is composed of 2000 samples for each uncertainty variables in the study. The choice of the uniform distribution law is justified by the fact that only the extreme values for each uncertain variable are provided and any other laws would give supplementary and arbitrary information.

Table 3 : Uncertainty variables

\begin{tabular}{|c|c|}
\hline Parameter & Perturbation \\
\hline Azimuth & $\boldsymbol{\alpha}^{\mp^{0.33^{\circ}}}$ \\
\hline Internal Vessel Radius & $R_{\text {intves }}^{ \pm 5.8 m m}$ \\
\hline Internal Envelope Radius & $R_{\text {intenv }}^{ \pm 4 m m}$ \\
\hline External Envelope Radius & $R_{\text {extEnv }}^{ \pm 1 \mathrm{~mm}}$ \\
\hline Internal Shield Radius & $R_{\text {intsh }}^{ \pm 4.8 m m}$ \\
\hline Capsule thickness & $E_{\text {capthick }}^{ \pm 0.38 m m}$ \\
\hline Water gap & $E_{\text {watgap }}^{ \pm 0.5 m m}$ \\
\hline Capsule position & $E_{\text {cappos }}^{ \pm 0.2 m m}$ \\
\hline Water temperature & $T_{\text {wat }}^{ \pm 1^{\circ}}$ \\
\hline
\end{tabular}

With URANIE a sensitivity analysis is also carried out, in order to evaluate if the variations of $\Phi_{1 \mathrm{MeV}}$ can be approached by a linear, additive or nonlinear form of the uncertainty variables, and also to determine the most influential ones in the point of interest.

Fig. 5 illustrates the impact of the nine variables on $\Phi_{1 \mathrm{MeV}}$ in the surveillance capsules and the vessel. One can observe that the relation between $\Phi_{1 \mathrm{MeV}}$ and the uncertainty variables is well fitted by a linear relation because the coefficient of determination $\mathrm{R}^{2}$ is higher than 0.99 . The sensitivities are thus simply proportional to the coefficient of the linear regression. Fig. 6 classes the sensitivities of the uncertainty variables in the surveillance capsules. In the $17^{\circ}$ capsule, the angular position, the water temperature, the internal radius of the shield and of the envelope have more important impact on $\Phi_{1 \mathrm{MeV}}$ than the other parameters because of much higher range of variation. A similar analysis shows that the vessel is very sensitive to its internal radius, and much less to the internal radii of the envelope and the shield. It is almost unaffected by other uncertain variables because of its distance from the core and the shielding effect produced by the interposed water. 


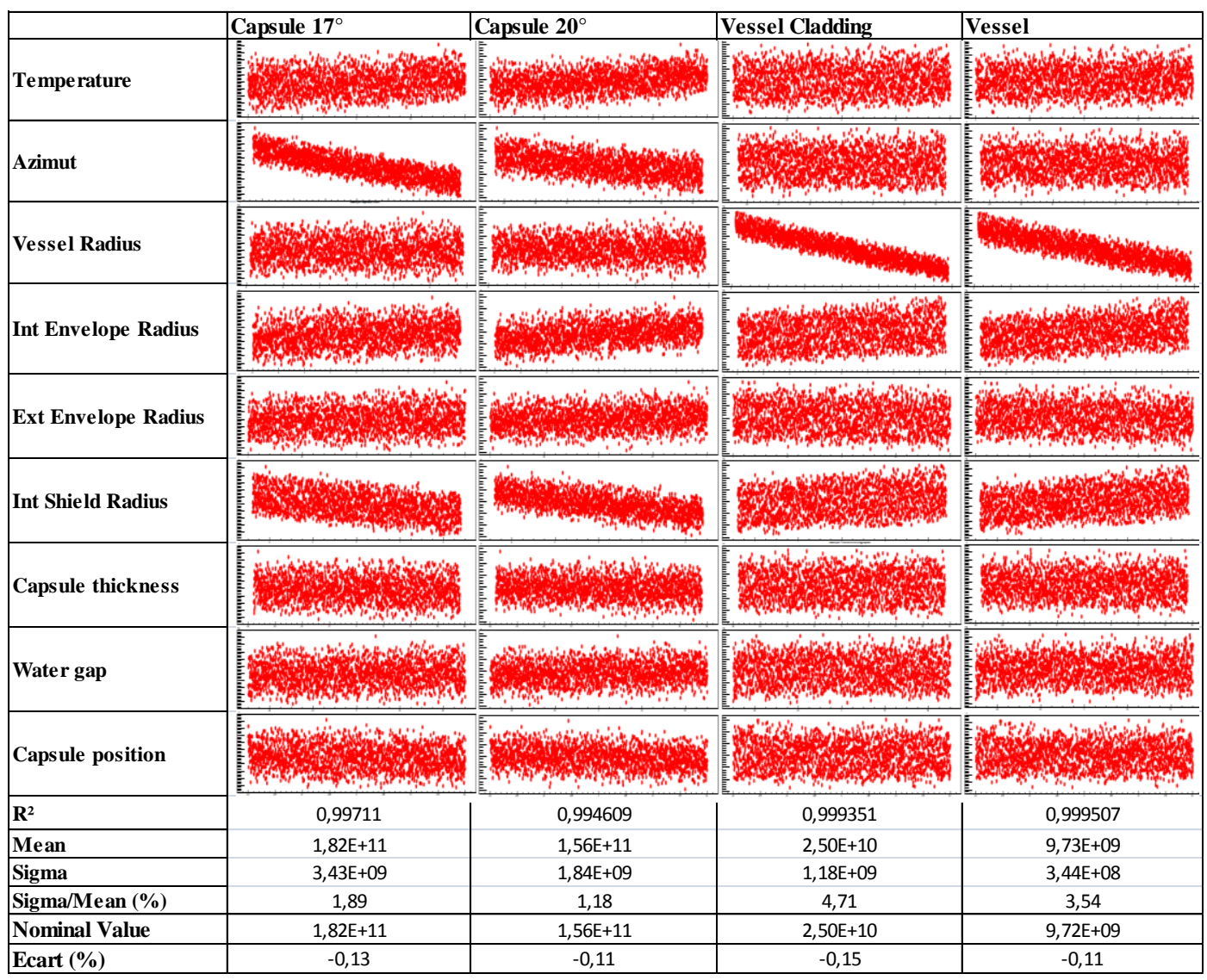

Figure 5 : DOE for the total flux over $1 \mathrm{MeV}$ in surveillance capsules, the vessel cladding and the vessel

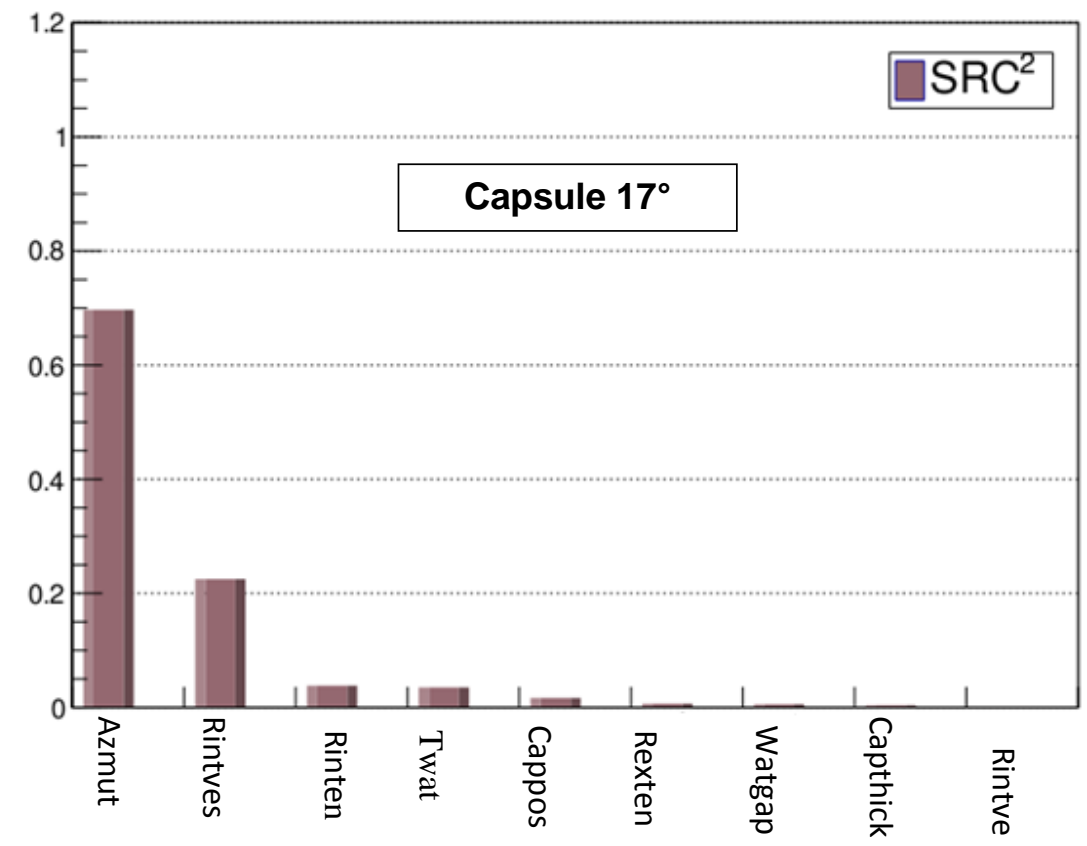

Figure 6 : Sensitivities of the total flux over $1 \mathrm{MeV}$ in the surveillance capsule $17^{\circ}$ 
Fig. 7 shows the impact of the uncertain variables on the multigroup flux in the surveillance capsules. The angular position is anti-correlated with the multigroup flux because the capsule gets closer to the vessel point of highest flux ("hot spot") when the angle decreases. The most impacted energetic range is between 1 and $3 \mathrm{MeV}$ because by approaching the peripheral assemblies the weight of the fission spectrum increases (energy range between 1 and $3 \mathrm{MeV}$ ) and the probability is higher that neutrons with lower energy reach the capsule. The shield internal radius and the multigroup flux are positively correlated in the range between 2 and $20 \mathrm{MeV}$, because the slowing-down power of the steel decreases due to the reduction of its corresponding thickness. On the other hand, the anti-correlation below $3 \mathrm{MeV}$ is due to a high neutron transfer below $1 \mathrm{MeV}$. This effect is produced by the increase of the water thickness and by the high cross-section value of the water in this energy range (Fig. 8).

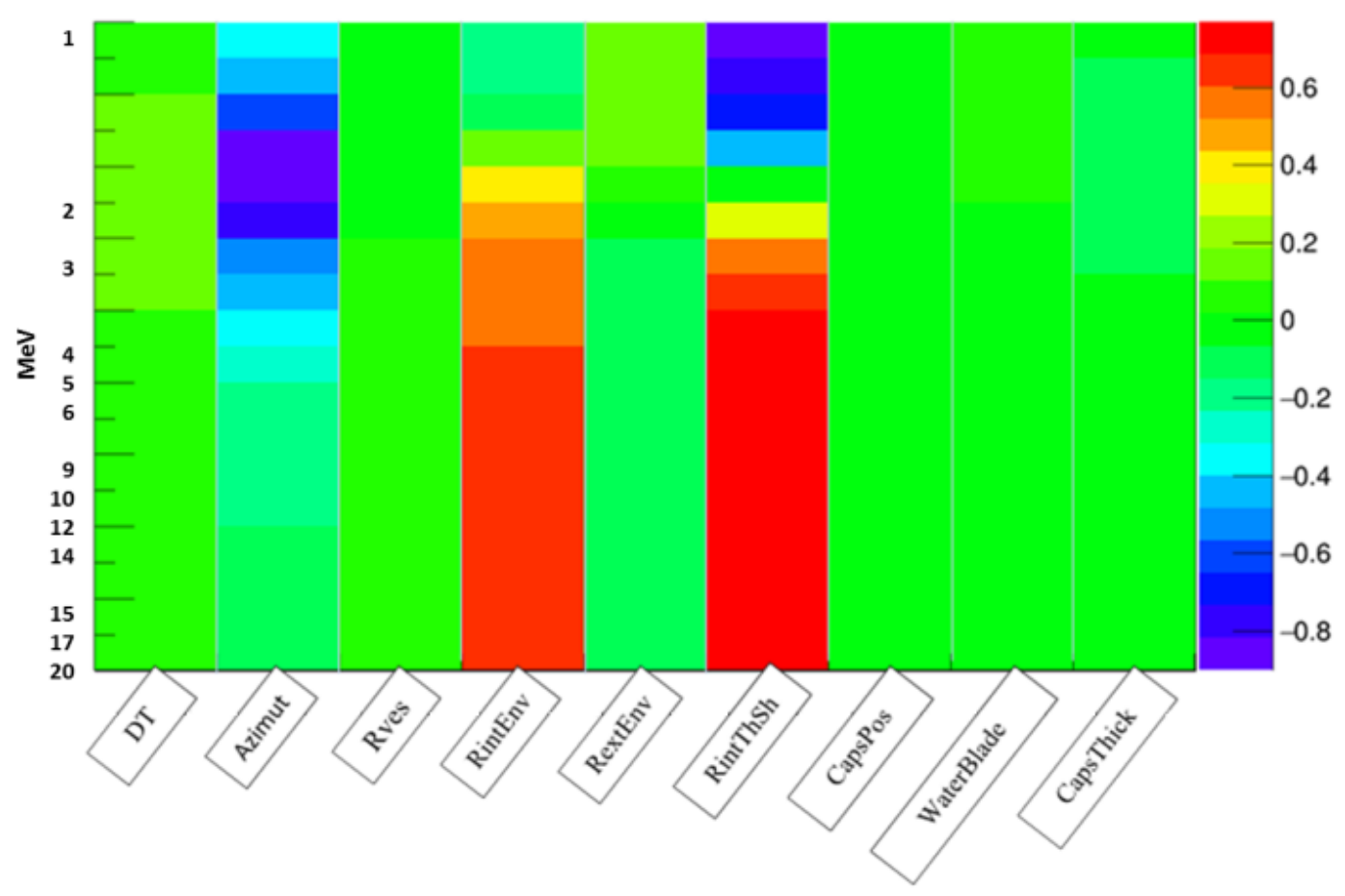

Figure 7: Correlation between variables and multigroup flux in the surveillance capsule. 


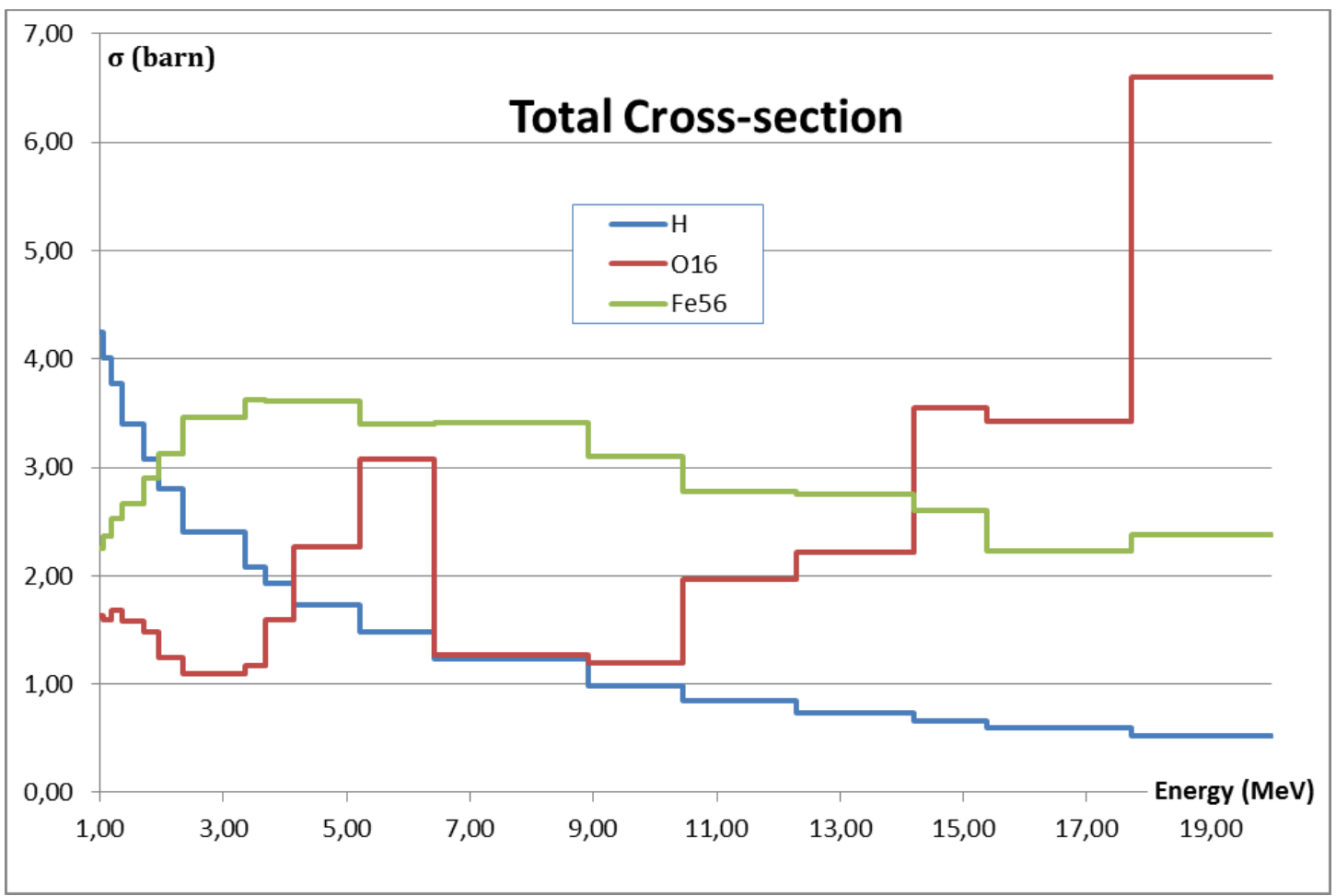

Figure 8: Multigroup total cross-sections of different isotopes

\section{CONCLUSIONS}

This paper shows the new deterministic fast fluence scheme with the APOLLO3 ${ }^{\circledR}$ code developed at CEA.

The use of sub-group self-shielded cross-section collapsed over an optimized collapsing energy mesh by AEMC allows to carry out very precise deterministic calculations of neutron flux in the vessel. Results of this deterministic model are encouraging, the integral of the flux over $1 \mathrm{MeV}$ in the location of interest is calculated in less than 20 minutes with an error lower than $1 \%$ with respect to the TRIPOLI- $4{ }^{\circledR}$ Monte Carlo reference.

An example of uncertainty propagation with the CEA uncertainty and sensitivity platform URANIE is also provided. This example offers an alternative approach to the classic first order sensitivity analysis to perform uncertainty studies like in [9]. It will be pursued in order to estimate the impact of nuclear data (cross-sections, fission spectra) and of other technological parameters (power distribution, power intensity ...).

The authors acknowledge EDF (Electricité De France) for the financial and technical support.

\section{References}

[1] D. Schneider et al, "APOLLO3 ${ }^{\circledR}:$ CEA/DEN deterministic multi-purpose code for reactor physics analysis", PHYSOR-2016, May 1-5 2016, Sun Valley, Idaho, USA

[2] J-Y. Moller - J-J. Lautard, "MINARET, a deterministic neutron transport solver for nuclear core calculations", M\&C 2011, May 8-12 2011, Rio de Janeiro, Brazil 
[3] P. Mosca et al., "An Adaptive Energy Mesh Constructor for Multigroup Library Generation for Transport Codes", NSE, 167, 40, 2011.

[4] "TRIPOLI-4 version 8.1, "3D general purpose continuous energy Monte Carlo Transport code", NEA-1716 TRIPOLI-4 VERS. 8.1, https://www.oecd-nea.org/tools/abstract/detail/nea-1716

[5] F. Gaudier, "URANIE: The CEA/DEN Uncertainty and Sensitivity platform", Procedia Social and Behavioral Sciences 2, 7660, 2010.

[6] P. Mosca et al., "Improvement in Transport Calculations by the Energy-Dependent Fission Spectra and Subgroup Method for Mutual Shielding", NSE, 175, 266, 2013.

[7] R. Sanchez et al., "APOLLO2 YEARS 2010", NET, 42, $474,2010$.

[8] P. Mosca et al., "Energy mesh optimization for multi-level calculation schemes", M\&C 2011, Rio de Janeiro, Brazil, 2011.

[9] I. Kodeli, "Multidimensional Deterministic Nuclear Data Sensitivity and Uncertainty Code System : Method and Application", NSE, 138, 45, 2001. 